\title{
PRODUÇÕES ACADÊMICAS SOBRE VIOLÊNCIA, AGRESSÃO E AGRESSIVIDADE EM PERIÓDICOS BRASILEIROS DE EDUCAÇÃO FÍSICA
}

\section{Elaine prodocimo}

Universidade Estadual de Campinas ,Campinas, São Paulo, Brasil

Aline santos souza

Universidade Estadual de Campinas ,Campinas, São Paulo, Brasil

André Cristiano Figueira

Universidade Estadual de Campinas ,Campinas, São Paulo, Brasil

Guilherme Oliveira Travagin

Universidade Estadual de Campinas ,Campinas, São Paulo, Brasil

Hildebrando Silva dos Santos

Universidade Estadual de Campinas ,Campinas, São Paulo, Brasil

Mayara de Oliveira Peres

Universidade Estadual de Campinas ,Campinas, São Paulo, Brasil

\section{Resumo}

O presente estudo tem como objetivo levantar e analisar as publicações sobre violência, agressão e agressividade em oito revistas brasileiras da Educação Física indexadas e classificadas nos extratos A2 a B2 do sistema Qualis - CAPES da área 21, nos últimos dez anos. Os artigos foram pesquisados pelas palavras-chave: violência, agressão e agressividade. A pesquisa foi feita nas revistas: Motriz, Movimento, Revista Brasileira de Ciências do Esporte, Revista Brasileira de Educação Física e Esporte, Revista Brasileira de Ciência e Movimento, Pensar a Prática, Revista da Educação Física, Revista Brasileira de Atividade Física e Saúde. Embora o tema seja importante e mesmo urgente, foram encontrados apenas 13 artigos $=0,60 \%$ do total de artigos publicados, o que representa uma baixa produção sobre a temática. Palavras chave: Violência. Agressão. Agressividade. Produção Acadêmica. 


\section{Introdução}

Segundo Coutinho et al. (2012) houve um aumento na produção na área da Educação Física a partir de 2001, acompanhando também o aumento de programas de Pós-Graduação stricto sensu e, consequentemente, de dissertações e teses.

Ainda segundo o autor, conhecer as produções de uma área é importante para a melhoria das pesquisas e para o diagnóstico do impacto das mesmas na realidade social em que foram produzidas. Rosa e Leta (2010), analisando as temáticas das produções na área a partir de artigos publicados em quatro revistas nacionais no período compreendido entre 2000 e 2005, concluíram que 77,14\% foram classificados na área Biológica, sendo a disciplina fisiologia a mais frequente, e $22,85 \%$ na área de Humanas, com a disciplina psicologia com maior número de artigos publicados, demonstrando uma prevalência de estudos na área da Saúde e afins.

É sabido, contudo, que este aumento da produção científica não necessariamente reflete uma melhoria em termos de valorização ou mesmo de condições para a atividade docente como um todo. Como apontam Marchlewski, Silva e Soriano (2011), este aumento de produção cumpre com necessidade de acúmulo de "capital científico" (p.106), sem necessariamente haver aplicação ou desdobramento do mesmo.

Em relação aos estudos sobre violência escolar, segundo Sposito (2001), as produções acerca do tema têm crescido e também alterado seu foco nas últimas décadas. Pesquisas realizadas na década de 80 mostravam preocupação em retratar a violência contra o patrimônio e a falta de condições físicas dos prédios escolares, com foco na segurança. No entanto, poucos estudos foram realizados, tanto por instituições de pesquisa ligadas aos órgãos governamentais quanto às universidades. Já na década de 90 , houve aumento nas produções, com maior inserção das universidades e estudos diagnósticos sobre a realidade escolar, aumentando também o interesse nos aspectos educativos especialmente no final dos anos 90 .

Diante do amplo espectro possível de estudos, interessa-nos conhecer e analisar o que foi publicado sobre a temática da violência nos últimos dez anos nos periódicos nacionais da Educação Física, indexados nos extratos A2 a B2 na área 21 da Coordenadoria de Aperfeiçoamento de Pessoal de Nível Superior - CAPES.

\section{Método}

Foram realizadas consultas com as palavras-chave (LAVILLE e DIONE, 1999) 'violência', 'agressão' e 'agressividade', e suas adjetivações

Pensar a Prática, Goiânia, v. 17, n. 3, p. 682-700, jul./set. 2014 
como 'violência escolar', em oito periódicos nacionais da subárea Educação Física da CAPES, indexados nos extratos mais altos: A2, B1 e B2 da área 21, durante o período compreendido entre Janeiro de 2003 e Março de 2013. Não foram consideradas revistas no extrato A1, pois no momento do estudo nenhuma revista nacional específica da Educação Física estava indexada neste extrato. A coleta de dados foi realizada junto aos sites de cada revista e também no material impresso para os casos da não disponibilidade on line, durante o período de Julho a Setembro de 2013.

As revistas analisadas a princípio foram: Revista Movimento; Revista Motriz; Revista Brasileira de Ciências do Esporte - RBCE; Revista Brasileira de Educação Física e Esporte; Revista Brasileira de Ciência e Movimento; Revista Pensar a Prática; Revista da Educação Física e Revista Brasileira de Atividade Física e Saúde. As seguintes revistas: Revista Brasileira de Ciência e Movimento; Revista da Educação Física e Revista Brasileira de Atividade Física e Saúde não publicaram nenhum artigo sobre o tema durante o período analisado e foram desconsideradas, restando as outras cinco.

A Revista Movimento é uma publicação da Escola de Educação Física da Universidade Federal do Rio Grande do Sul - UFRGS, atualmente tem periodicidade trimestral, e estava indexada como A2 no Web Qualis CAPES durante o período da coleta dos dados. A Revista Motriz é publicação do Departamento de Educação Física da Universidade Estadual de São Paulo UNESP, com periodicidade trimestral e estava também indexada como A2. A Revista Brasileira de Ciências do Esporte é editada pelo Colégio Brasileiro de Ciências do Esporte, tem periodicidade trimestral e estava indexada como B1. A Revista Brasileira de Educação Física e Esporte é uma publicação da Escola de Educação Física e Esporte da Universidade de São Paulo USP, tem periodicidade trimestral e estava indexada como B1, e até o ano de 2003, este periódico possuía o nome de Revista Paulista de Educação Física. A Revista Pensar a Prática é uma publicação da Faculdade de Educação Física da Universidade Federal de Goiás - UFG, tem periodicidade trimestral e estava indexada como B2.

Os artigos selecionados por meio da referida busca foram analisados na íntegra por meio do procedimento de análise de conteúdo. Segundo Laville e Dione (1999, p. 214): “[...] consiste em desmontar a estrutura e os elementos desse conteúdo para esclarecer suas diferentes características e extrair sua significação".

Foi realizado, inicialmente, um levantamento quanto a: quantidade de artigos em cada periódico e a relação com o total de artigos publicados pelo periódico no período; organização do artigo, levando em conta número, gênero e filiação dos autores; abordagem metodológica utilizada; temática

Pensar a Prática, Goiânia, v. 17, n. 3, p. 682-700, jul./set. 2014 
tratada; e, finalmente, análise dos conteúdos abordados e a relação entre o tema e a Educação Física propriamente dita.

Os artigos caracterizados neste estudo foram nomeados por T1, T2, T3 e assim sucessivamente, de acordo com a revista, acompanhando o extrato CAPES e a ordem cronológica de publicação em cada periódico, obedecendo a seguinte ordem das revistas: Movimento, Motriz, Revista Brasileira de Ciências do Esporte, aqui denominada RBCE, Revista Brasileira de Educação Física e Esporte, aqui denominada RBEFE e Pensar a Prática.

\section{Resultados e Discussões}

1- Caracterizando os artigos

Foram levantados 13 artigos com as palavras-chave: 'violência', 'agressividade' e 'agressão' nos periódicos consultados, envolvendo o período de Janeiro de 2003 a Abril de 2013 (Tabela 1).

Tabela 1: Total de artigos publicados sobre a temática por revista e por ano, durante o período do estudo.

\begin{tabular}{|c|c|c|c|c|c|c|c|c|c|c|c|c|}
\hline \multirow{2}{*}{ Periódicos } & \multicolumn{11}{|c|}{ Ano de publicação } & \multirow{2}{*}{ Total } \\
\hline & 03 & 04 & 05 & 06 & 07 & 08 & 09 & 10 & 11 & 12 & 13 & \\
\hline Movimento & - & - & - & - & - & - & - & - & - & T1 & - & 1 \\
\hline Motriz & $\mathrm{T} 2$ & - & - & - & - & - & - & - & $\mathrm{T} 3$ & $\mathrm{~T} 4$ & - & 3 \\
\hline RBCE & - & - & - & - & - & $\mathrm{T} 5$ & - & - & - & - & - & 1 \\
\hline RBEFE & T6 & - & - & - & - & - & - & - & - & $\mathrm{T} 7$ & - & 2 \\
\hline Pensar a Prática & - & - & - & - & - & $\mathrm{T} 8$ & $\begin{array}{l}\text { T9 } \\
\text { T10 }\end{array}$ & $\begin{array}{l}\text { T11 } \\
\text { T12 }\end{array}$ & - & $\mathrm{T} 13$ & - & 6 \\
\hline Total & 2 & 0 & 0 & 0 & 0 & 2 & 2 & 2 & 1 & 4 & 0 & 13 \\
\hline
\end{tabular}

É possível verificar que a revista com maior número de artigos publicados sobre o tema foi a Pensar a Prática, com seis artigos entre os 13 obtidos, $(46,15 \%)$, seguida pela Motriz, com três artigos $(23,07 \%)$. O ano em que houve maior número de publicações foi 2012, com quatro artigos $(30,77 \%)$. Entre os anos de 2004 e 2007 nenhum artigo foi publicado com as palavras-chave analisadas.

Quando investigamos o número de artigos sobre a temática da violência em relação ao total de artigos publicados, temos (Tabela 2):

Pensar a Prática, Goiânia, v. 17, n. 3, p. 682-700, jul./set. 2014 
Tabela 2: Porcentagem dos artigos em relação ao total de publicações no período

\begin{tabular}{l|ll}
\hline Periódicos & Total de artigos publicados & $\begin{array}{l}\text { Total e \% de artigos publicados com o } \\
\text { tema violência }\end{array}$ \\
\hline Movimento & 393 & $1(0,25 \%)$ \\
Motriz & 628 & $3(0,48 \%)$ \\
RBCE & 459 & $1(0,22 \%)$ \\
RBEFE & 353 & $2(0,57 \%)$ \\
Pensar a Prática & 317 & $6(1,89 \%)$ \\
\hline Total & 2150 & $13(0,60 \%)$ \\
\hline
\end{tabular}

Durante os dez anos investigados, apenas 13 artigos $(0,60 \%)$ foram publicados na área da violência em suas diferentes manifestações e nas diferentes áreas da Educação Física. Este dado contrasta com dados mundiais que revelam aumento dos estudos na área.

$\mathrm{Na}$ busca de compreender este quadro poderíamos levantar algumas hipóteses: são realizados estudos em forma de dissertações e teses, mas os mesmos não vêm sendo publicados em periódicos especializados, ou vêm sendo publicados em periódicos de outras áreas e não especificamente na área da Educação Física, como revistas de Psicologia ou Educação; também é possível analisar que artigos tenham sido publicados com outras palavraschave, não tendo sido incluídos no presente estudo; ou ainda, que as pesquisas com foco neste tema têm sido incipientes na Educação Física.

Não é possível concluir que este tema não se apresenta como relevante para a área, contudo não nos foi possível identificar, pelo levantamento realizado, a razão para tão poucas produções. Marchlewski, Silva e Soriano (2011) fazem um alerta sobre o quanto a busca por prestigio e reconhecimento acadêmico por meio da produção excessiva de artigos pode levar a uma desconsideração sobre questões que emergem da sociedade e que merecem atenção da comunidade científica e dos envolvidos na produção de conhecimento.

Em relação ao número de autores foram computados 44 autores no total, sendo que: dois textos foram escritos com autoria única, três deles com dupla autoria, outros dois com três autores e os seis restantes em grupo de autores. Este resultado contrasta com os dados obtidos por Rosa e Leta (2010), nos quais 65,5\% do total dos artigos analisados na área da Educação Física foram produzidos por até três autores. No caso aqui analisado a porcentagem obtida foi de 53,85\% para textos com até três autores.

Quanto ao sexo, dos 44 autores foram considerados 41 - três autores publicaram dois trabalhos, sendo uma mulher e dois homens - desse total, 18 eram mulheres $(43,90 \%)$ e 23 eram homens $(56,10 \%)$. Considerando apenas o gênero do primeiro autor, obtivemos sete mulheres $(53,85 \%)$ e seis

Pensar a Prática, Goiânia, v. 17, n. 3, p. 682-700, jul./set. 2014 
homens $(46,15 \%)$. Estes dados também contrastam com o obtido por Rosa e Leta (2010), cuja análise reportou 45\% de mulheres como primeiras autoras dos textos investigados.

Sobre as instituições de proveniência dos autores temos que nove são de universidades públicas, dois de universidades particulares, um de uma universidade pública em conjunto com uma Secretaria de Educação e um em conjunto entre universidade pública e privada. A prevalência de autores de instituições públicas também foi obtida no estudo de Rosa e Leta (2010) e de Coutinho et al (2012).

Quanto às palavras-chave utilizadas, 11 reportam-se à violência, dois à agressividade e nenhum à agressão.

Sobre a abordagem metodológica utilizada, houve predomínio de pesquisas de campo, com oito estudos publicados, mais dois trabalhos com pesquisa de campo acrescida de análise documental e três estudos de revisão bibliográfica.

2- $\quad$ Relação com áreas da Educação Física

Sobre as áreas da Educação Física abordadas, os artigos foram distribuídos em três grandes grupos: esporte, escolar e lazer, conforme exposto no Quadro 1.

Quadro 1: Informações sobre artigo: periódico, autoria, título, palavrachave e área da Educação Física

\begin{tabular}{|c|c|c|c|c|c|}
\hline $\begin{array}{l}\text { Arti } \\
\text { go }\end{array}$ & Revista & Autor & Título & $\begin{array}{l}\text { Palavras } \\
\text { - chave }\end{array}$ & Área \\
\hline $\mathrm{T} 1$ & Movimento & Reis (2012) & $\begin{array}{l}\text { Lei geral da copa, álcool e } \\
\text { o processo de criação da } \\
\text { legislação sobre violência }\end{array}$ & Violência & Esporte \\
\hline $\mathrm{T} 2$ & Motriz & $\begin{array}{l}\text { Staprepravo e } \\
\text { Mezzadri } \\
\text { (2003) }\end{array}$ & $\begin{array}{l}\text { Esporte, Relações Sociais } \\
\text { e Violências }\end{array}$ & Violência & Esporte \\
\hline T3 & Motriz & $\begin{array}{l}\text { Levandoski, } \\
\text { Ogg e Cardoso } \\
\text { (2011) }\end{array}$ & $\begin{array}{l}\text { Violência } \\
\text { professores de Educação } \\
\text { Física no ensino público } \\
\text { do Estado do Paraná }\end{array}$ & $\begin{array}{l}\text { Violência } \\
\text { Escolar }\end{array}$ & Escolar \\
\hline $\mathrm{T} 4$ & Motriz & $\begin{array}{l}\text { Palhares, et al } \\
(2012)\end{array}$ & $\begin{array}{l}\text { Lazer, agressividade e } \\
\text { violência: considerações } \\
\text { sobre o comportamento } \\
\text { das torcidas organizadas }\end{array}$ & Violência & Esporte \\
\hline T5 & RBCE & $\begin{array}{l}\text { Campos, et al } \\
(2008)\end{array}$ & $\begin{array}{l}\text { As determinações do } \\
\text { Estatuto de defesa do } \\
\text { torcedor sobre a questão da } \\
\text { violência: a segurança do }\end{array}$ & Violência & Esporte \\
\hline
\end{tabular}

Pensar a Prática, Goiânia, v. 17, n. 3, p. 682-700, jul./set. 2014 


\begin{tabular}{|c|c|c|c|c|c|c|}
\hline & & & & $\begin{array}{l}\text { torcedor de futebol na } \\
\text { apreciação do espetáculo } \\
\text { esportivo }\end{array}$ & & \\
\hline T6 & RBEFE & & Reis (2003) & $\begin{array}{l}\text { Os espectadores de futebol } \\
\text { e a problemática da } \\
\text { violência relacionada à } \\
\text { organização do espetáculo } \\
\text { futebolístico }\end{array}$ & Violência & Esporte \\
\hline $\mathrm{T} 7$ & RBEFE & & $\begin{array}{l}\text { Salvini, } \\
\text { Souza, e } \\
\text { Marchi } \quad \text { Jr. } \\
(2012)\end{array}$ & $\begin{array}{l}\text { A violência simbólica e a } \\
\text { dominação masculina no } \\
\text { campo esportivo: algumas } \\
\text { notas e digressões teóricas }\end{array}$ & $\begin{array}{l}\text { Violência } \\
\text { Sim- } \\
\text { bólica }\end{array}$ & Esporte \\
\hline T8 & $\begin{array}{l}\text { Pensar } \\
\text { Prática }\end{array}$ & $\mathrm{a}$ & $\begin{array}{l}\text { Albino, et al } \\
(2008)\end{array}$ & $\begin{array}{l}\text { Acerca da violência por } \\
\text { meio do futebol no ensino } \\
\text { de Educação Física: } \\
\text { retratos de uma prática e } \\
\text { seus dilemas }\end{array}$ & Violência & Escolar \\
\hline T9 & $\begin{array}{l}\text { Pensar } \\
\text { Prática }\end{array}$ & $\mathrm{a}$ & $\begin{array}{l}\text { Silva e Votre } \\
(2009)\end{array}$ & $\begin{array}{lrr}\text { Encanto } & \text { e } & \text { fascínio: } \\
\text { dimensões } & \text { da } & \text { sedução na } \\
\text { educação } & & \\
\end{array}$ & Violência & Escolar \\
\hline $\mathrm{T} 10$ & $\begin{array}{l}\text { Pensar } \\
\text { prática }\end{array}$ & $\mathrm{a}$ & $\begin{array}{l}\text { Candreva, et } \\
\text { al (2009) }\end{array}$ & $\begin{array}{l}\text { A agressividade na } \\
\text { educação infantil: o jogo } \\
\text { como forma de interven- } \\
\text { ção }\end{array}$ & $\begin{array}{l}\text { agressivi } \\
\text { dade }\end{array}$ & Escolar \\
\hline T11 & $\begin{array}{l}\text { Pensar } \\
\text { prática }\end{array}$ & $\mathrm{a}$ & $\begin{array}{l}\text { Mello, et al } \\
(2010)\end{array}$ & $\begin{array}{l}\text { A construção da rivalidade } \\
\text { e da violência entre os } \\
\text { grupos de capoeira de } \\
\text { Piúma/ES }\end{array}$ & Violência & Lazer \\
\hline T12 & $\begin{array}{l}\text { Pensar } \\
\text { prática }\end{array}$ & $\mathrm{a}$ & $\begin{array}{l}\text { Levandoski e } \\
\text { Cardoso } \\
(2010)\end{array}$ & $\begin{array}{lr}\text { Percepção docente } & \text { sobre } \\
\text { as relações } & \text { de } \\
\text { agressividade, o lúdico e o } \\
\text { "bullying" na escola }\end{array}$ & $\begin{array}{l}\text { Agressivi } \\
\text { dade }\end{array}$ & Escolar \\
\hline T13 & $\begin{array}{l}\text { Pensar } \\
\text { prática }\end{array}$ & $\mathrm{a}$ & $\begin{array}{l}\text { Bomfim, etAL } \\
\text { (2012) }\end{array}$ & 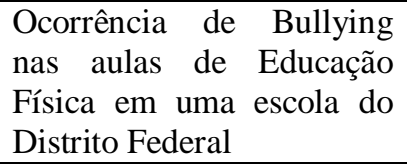 & $\begin{array}{l}\text { Violência } \\
\text { na Escola }\end{array}$ & Escolar \\
\hline
\end{tabular}

\section{$2.1-$ Esporte}

Sobre este tema, foram levantadas duas subcategorias:

\subsection{1- Torcidas}

Quatro dos 13 textos analisados tratam a respeito de torcidas: T1, de autoria de Reis (2012), trata principalmente da questão dos megaeventos e

Pensar a Prática, Goiânia, v. 17, n. 3, p. 682-700, jul./set. 2014 
das leis estabelecidas para sua concretização no que diz respeito à venda de bebidas alcoólicas nos estádios e da interferência da FIFA no estabelecimento; T4, de autoria de Palhares, Schwartz, Teruel, Santiago e Trevisan (2012), faz análise da relação entre as torcidas organizadas e a violência nos estádios de futebol, apresenta também o lazer no título e nas palavras-chave; em T5, de autoria de Campos, Melo, Abrahão e Silva (2008), o tema tratado é a relação entre o estatuto do torcedor, ocorrências em dias de jogos e a sensação de segurança nos estádios e fora deles; em T6 também de autoria de Reis (2003), é feita uma comparação entre Brasil e Espanha no que diz respeito à prevenção da violência entre torcedores nos jogos de futebol.

Embora a questão da torcida diga respeito também à prática de lazer, foram considerados nesta categoria por tratarem do esporte como espaço/tempo para sua realização.

\subsection{2- Práticas esportivas}

Dois dos 13 textos dizem respeito ao tema: T2, da autoria de Starepravo e Mezzani (2003), trata das origens do esporte pautado em Norbert Elias e Eric Dunning e investiga a relação entre esporte e diminuição da violência social; em T7, de autoria de Salvani, Souza e Marchi Junior (2012), o assunto tratado é a violência simbólica sofrida pelas mulheres na prática esportiva.

\section{$2.2-$ Escolar}

Sobre este tema também duas categorias foram levantadas:

\subsection{1- Relações Pessoais}

Quatro dos 13 textos estudados reportam-se à questão das relações pessoais na escola e à violência. Em T3, de autoria de Levandoski, Ogg e Cardoso (2011), o tema tratado é a violência vivenciada e percebida por professores; em T9 de autoria de Silva e Votre (2009), é investigada a relação professor-aluno no que diz respeito à sedução e ao fascínio na prática pedagógica; em T12, também de autoria de Levandoski e Cardoso (2010), o tema tratado é a maneira como os alunos percebem e lidam com as situações de conflito e a presença de bullying entre os pares; em T13, de autoria de Bomfim, Campbell, Moraes, Franco, Cunha, França e Ferreira (2012), o tema tratado é o bullying nas aulas de Educação Física.

\subsection{2- Prática Pedagógica}

Pensar a Prática, Goiânia, v. 17, n. 3, p. 682-700, jul./set. 2014 
Dois dos 13 artigos tratam da questão pedagógica e sua relação com a violência. Em T8, de autoria de Albino, Zeiser, Bassani e Vaz (2008), o tema tratado é o futebol como forma de sensibilizar sobre o tema da violência nas aulas de Educação Física. T10, de autoria de Candreva, Cassiane, Ruy, Thomazini, Cestari e Prodócimo (2009) trata do jogo como forma de intervenção quanto ao tema da agressividade no Ensino Infantil.

\section{$2.3-$ Lazer}

Apenas um artigo foi considerado dentro da temática do lazer: T11, da autoria de Mello, Costa, Santos e Ferreira Neto (2010), que trata das relações entre grupos rivais de capoeira e a violência entre eles. Como já apresentado, embora T4 traga no título e nas palavras-chave o lazer, por se tratar de torcidas, no presente estudo foi considerado na área do esporte pela proximidade com os outros textos da temática.

É possível verificar certo equilíbrio entre os trabalhos publicados nas temáticas de escolar e esporte, com seis trabalhos cada, havendo distribuição também quanto ao assunto tratado, porém, poucos trabalhos foram publicados mais especificamente na área do lazer.

\section{3- $\quad$ Aspectos abordados nos artigos levantados}

Após a leitura completa dos textos levantados foi possível verificar que diferentes aspectos sobre a temática da violência foram abordados pelos autores. A partir dessa percepção foi realizada categorização em quatro grandes grupos: conceitos e tipos de violência; causas de violência; violência e as relações de gênero; prevenção e condutas tomadas quanto à violência.

\section{1 - Conceitos e Tipos de Violência}

Neste levantamento realizado percebeu-se que, embora os artigos se propusessem a discutir a relação entre a violência e/ou agressividade e diferentes temas da Educação Física, nem todos apresentam a conceituação dos termos utilizados. É possível verificar nos estudos sobre o tema uma certa confusão em relação ao que é entendido como violência e agressividade, suas distinções e/ou similaridades (PRODÓCIMO et al, 2013).

Nos textos analisados esta situação não foi diferente. Foi possível perceber que em alguns artigos os dois conceitos são utilizados como sinônimos, ora sendo referenciada a violência ora a agressividade, sem distin- 
ção, demonstrando certa confusão entre os conceitos. Em outros artigos, o comportamento agressivo é descrito como uma das possibilidades da violência, aliado aos comportamentos antissociais e aos conflitos. Alguns não se reportam a conceituações, porém utilizam apenas um dos dois termos, mantendo coerência com a opção feita. E há ainda textos que optam por conceituar formas específicas de violência, como a violência simbólica ou o bullying.

Os conceitos apresentados variam de acordo com as bases teóricas adotadas, porém, todos convergem no sentido de que ambos são comportamentos de uma pessoa ou grupo de pessoas contra outrem, com a intenção de causar danos ou impor algo.

Por tratar-se de fenômeno multidimensional, diferentes olhares são direcionados ao mesmo e, na busca de elucidação, pautamo-nos em Ribolla e Fiamenghi Jr. (2007, p.114) que, com base em Osório (1999) descrevem:

\begin{abstract}
A agressividade é a propulsão para a ação, necessária para nos impulsionarmos em nossos propósitos, tanto nos construtivos quanto nos destrutivos. Já o termo agressão possui o caráter negativo e destrutivo da agressividade. A violência estaria situada no extremo da conduta agressiva que possua fins destrutivos.
\end{abstract}

Sobre as formas de violência, nos 13 artigos analisados, a violência física, caracterizada pelo excesso de força corporal ou armada, apareceu com mais frequência, seguida pelas violências: simbólica - compreendida como a dominação consentida, na qual as pessoas, por meio de normas e princípios tidos como comuns, aceitam e não criticam a dominação; verbal por meio de xingamentos, ameaças; psicológica e social - com exclusões, segregação; e também violência sexual.

\title{
3.2- Causas da Violência
}

Um dos fatores apontados, especialmente nos textos que tratam do esporte, é o consumo de bebidas alcoólicas. Tal fator, segundo Reis (2012), estimula a violência e a impetuosidade, pois é capaz de levar o jovem a assumir atitudes de risco, já que diminui o poder de avaliação. Segundo Reis e Romera, (2011, apud Reis 2012, p. 81-82):

[...] A falsa sensação estimulante que a bebida provoca nas primeiras doses, inibe a crítica e a capacidade de julgamento dos bebedores, assim como potencializa os sentimentos, dando a eles uma sensação de liberdade para

Pensar a Prática, Goiânia, v. 17, n. 3, p. 682-700, jul./set. 2014 
expressar-se verbal e corporalmente, que muitas vezes leva-os a agirem de forma mais violenta, corajosa e perigosa.

Ainda com relação ao esporte e eventos esportivos, são apontados fatores como a falta de organização na venda de ingressos, filas gigantescas, ação de cambistas e falsificações como agravantes para incentivar condutas de revolta e violência entre os torcedores; e também a impunidade, pois leis aplicadas aos incidentes de violência envolvendo torcedores de futebol apenas são as constantes do código penal brasileiro, sem um tratamento especial em termos de legislação para os eventos esportivos, o que dificulta o andamento de processos e torna os casos, na maioria das vezes, impunes.

De maneira mais geral, é colocada a mídia como disseminadora de valores apresentando uma grande influência no sentido de incitar ou inibir manifestações violentas, desde a veiculação de declarações de apresentadores exaltando rivalidades existentes no esporte, até o conteúdo apresentado, como grande número de desenhos, filmes e noticiários com foco na violência.

No âmbito escolar os desgastes emocionais dos professores oriundos de um meio circundado pelo medo e insegurança são apontados. Também aulas que enfatizam rivalidades, competição e comparações podem gerar comportamentos violentos entre os alunos. $\mathrm{O}$ contexto familiar é apontado como causador de violência, pois, contextos familiares coercivos, punitivos, com ameaças e provocações entre os membros, contribuem para o aumento de manifestações violentas nas crianças. Tais aspectos familiares levam a uma formação moral deturpada, fazendo com que sejam adotados comportamentos violentos em diferentes ambientes, como a escola.

As tensões excessivas do dia a dia são apontadas também como fatores que levam à violência, e o jogo e o esporte são possibilidades de manifestar a violência de forma socialmente aceitável:

[...] no convívio social, o monopólio da violência física por parte do Estado, aliado aos padrões sociais vigentes, levam os indivíduos a ter um baixo limiar de aceitação quanto aos atos de violência, assim conduz as crianças a um maior autocontrole, de forma racional. A prática esportiva, por outro lado, permite certos atos de maior violência, bem como constituem uma válvula de escape das tensões do dia-a-dia (STAREPRAVO e MEZZADRI, 2003, p.62).

Pensar a Prática, Goiânia, v. 17, n. 3, p. 682-700, jul./set. 2014 
Dessa forma, estes conteúdos podem auxiliar os professores no trabalho com as questões das emoções e da violência no contexto das aulas de Educação Física (PRODÓCIMO et al, 2007).

\section{1 - Sexo}

Dos 13 artigos, cinco abordaram a questão do gênero de forma relevante na pesquisa. Albino et al. (2008) apresentam uma intervenção na escola, utilizando o futebol para melhorar os conflitos de gênero e violência, tentando propiciar uma maior participação das meninas no jogo, com regras adaptadas. Porém, mesmo assim as meninas continuavam com baixa participação, desmotivando toda a classe. Tal dado corrobora com outro artigo, de Levandoski e Cardoso (2010), que apontam que a frustração de mulheres em experienciar atividades esportivas pode ser um resultado da falta de participação, levando a certa repulsa quando colocadas frente ao estímulo motor, situação diferente da vivida pelos meninos.

Por outro lado, como apontado por Salvini et al. (2012), a mulher atleta sofre da violência simbólica, pois há, em nosso país, uma dominação dos esportes pelo universo masculino, principalmente o futebol, com o "predomínio" da força como legitimação para a essa prática. $\mathrm{O}$ artigo diz ainda que "[...] as diferenças biológicas são evocadas e mobilizadas no sentido de fundamentar as diferenças sociais [...]" (idem, p. 405).

Ainda no futebol, segundo Palhares et al. (2012), as torcidas organizadas apresentam a virilidade como uma de suas características. Para os autores, pautados em Reis (2006), o futebol possui acentuadas características de masculinidade, virilidade e força desde sua origem, envolvendo atletas, gestores e chegando até aos torcedores.

A ideia da virilidade associada à violência leva a uma "naturalização" da mesma. É aprendida e internalizada muitas vezes sem questionamentos, podendo ter caráter mimético ao se espelhar em quem a pratica, ou utilizada como forma de aceitação para fazer parte de um grupo. Isso pode fazer com que os jovens, ao almejarem o status de serem homens, sejam influenciados pelo modelo hegemônico de masculinidade associado à dominação e ao ser forte, pois a formação da identidade masculina passa também pelo lidar com a violência (NASCIMENTO, GOMES e REBELLO, 2009).

Podemos ver essa "sede" pela dominação no artigo de Mello et al (2010) sobre capoeira, em que muitas falas das entrevistas referenciam "os caras", "uns coroas" ou "os mestres". Um dos fatores apontados para a rivalidade entre os grupos se dá pelo embate físico, pela valentia, pela competição, pela mostra de maior força e domínio corporal do que o outro. Estes aspectos estão ligados socialmente à masculinidade. Assim como no futebol,

Pensar a Prática, Goiânia, v. 17, n. 3, p. 682-700, jul./set. 2014 
no grupo de capoeiristas estudado há a manifestação de violência simbólica por meio da exclusão, pois quando algo é tomado como natural (neste caso a visão que se tem de homens fortes e valentes sempre dispostos à briga) há a possibilidade de não inclusão de pessoas que não possuam o perfil do grupo.

Essa relação entre o masculino e as brigas também foi estudada no contexto escolar por Levandoski e Cardoso (2010), em que a maior parte dos meninos relaciona-se com mais situações violentas na escola quando comparados às meninas.

Estudos apontam diferenças nas formas de manifestações violentas entre meninos e meninas, ou entre homens e mulheres. Os meninos tendem a agir de forma mais direta, que pode ser mais facilmente observada, enquanto as meninas agem de forma mais indireta, por meio de humilhações e exclusões (PRODÓCIMO et al, 2010, PRODÓCIMO et al, 2013). Esta situação reforça a percepção de que homens são mais violentos, pois seus atos são mais "visíveis", e também reforça e/ou é reforçada pela ideia de virilidade apontada nos textos analisados e também na ideia da fragilidade feminina.

\section{4 - Prevenção da violência e condutas tomadas sobre a ação violenta}

No âmbito da prevenção da violência, bem como das condutas tomadas acerca das ações violentas, dentre os artigos que levantam e apontam esses aspectos notam-se algumas aproximações entre os estudos analisados, sobretudo àqueles que se remetem a discussões sobre temáticas similares.

É o caso dos artigos que abordam a temática da violência dentro do contexto escolar. Em linhas gerais, esses trabalhos ressaltam e alertam para a importância e a necessidade de se atentar às manifestações violentas, bem como discutir práticas de intervenções, seja por meio da participação da comunidade escolar, seja pelo desenvolvimento de ações sociais e pedagógicas, mediando os conflitos entre os alunos, de modo a minimizar tais cenários.

Candreva et al. (2009) indicam que algumas formas de lidar com o comportamento violento estariam na

[...] valorização de atitudes positivas, um trabalho em conjunto com toda a equipe escolar e um trato não só com as crianças agressivas, mas também com as empáticas se contrapondo a uma educação coercitiva podendo assim intervir no problema. (p. 09).

Pensar a Prática, Goiânia, v. 17, n. 3, p. 682-700, jul./set. 2014 
Outro enfoque levantado na análise proposta neste estudo remeteria ao contexto da temática do esporte, mais especificamente no universo das manifestações provenientes do futebol de alto rendimento, como é o caso da violência permeada entre as torcidas organizadas.

Nesses textos encontra-se uma unanimidade que exprime a importância da criação e implementação de políticas públicas adequadas que supram as necessidades apontadas por essas manifestações sociais, as torcidas. Elas compõem os espetáculos futebolísticos e acabam por protagonizar ações violentas por decorrência de diversos fatores, dentre eles, o consumo excessivo de bebidas alcoólicas.

Esse pressuposto fica claro por meio das falas de Reis (2003, p.91), ao apontar que:

[...] é necessário o trabalho conjunto de vários segmentos ligados ao futebol como espetáculo, incluindo aí o poder público, com sua grande parcela de responsabilidade sobre a segurança dos cidadãos e das cidadãs. Para isso, é necessária a criação de leis que regulamentem a ação da polícia, assim como sirvam de suporte para as ações no campo jurídico.

\section{Considerações Finais}

A Educação Física é uma área ampla, que tem expandido cada vez mais seus estudos nos diferentes campos de ação, acompanhando tendência atual da ciência não apenas brasileira, mas também mundial. Também o tema violência tem despertado cada vez mais interesse de pesquisas em diferentes áreas do conhecimento.

Na perspectiva da necessidade de conhecer o que vem sendo produzido sobre a violência, a fim de avaliar o impacto social dos estudos realizados, vemos que a temática tem sido pouco explorada, dado observado pelo pequeno número de publicações encontradas nos principais periódicos brasileiros indexados da área 21.

Como apontado anteriormente, esta falta de publicações pode dar-se por fatores como: a não publicação dos trabalhos nas revistas da Educação Física, pois, por tratar-se de tema relacionado também a outras áreas, periódicos da educação, da psicologia entre outros seriam também locais possíveis para submissão de trabalhos; o uso de indexadores diferentes dos analisados no presente estudo; ou pode realmente apontar para a falta de produção de trabalhos na área, por meio de dissertações e/ou teses sobre o assunto.

Pensar a Prática, Goiânia, v. 17, n. 3, p. 682-700, jul./set. 2014 
Por tratar-se de fenômeno multidimensional, o estudo da violência é realizado por diferentes olhares, com diferentes bases epistemológicas, o que leva a uma variação em relação à sua própria conceituação. Isso nos mostra a necessidade de mais trabalhos, para que assim possamos melhorar a compreensão dos termos e aumentar a discussão na sociedade brasileira.

Entre os trabalhos analisados encontramos também um campo abrangente, acompanhando a própria característica da Educação Física, cujos temas não se limitam em apenas um assunto, mostrando a variedade de locais e formas em que a violência se manifesta, como no âmbito esportivo, escolar ou nas atividades de lazer.

Chama a atenção a quantidade de trabalhos voltados para a questão das torcidas (quatro entre os seis publicados na área do esporte), demonstrando uma preocupação com os fatos sociais ocorridos nos últimos anos, em que a violência se manifesta de forma mais intensa, inclusive com casos de mortes.

Contudo, para além destes episódios que são mais largamente veiculados pela mídia, há outras formas de violência, mais veladas, que ocorrem cotidianamente nos diferentes contextos da prática da Educação Física e do esporte, e que poderiam e deveriam ser mais amplamente estudados, pois interferem na atuação docente.

\title{
ACADEMIC PRODUCTIONS ABOUT VIOLENCE, AGGRESSION AND AGRESSIVENESS IN BRAZILIANS JOURNALS AT PHYSICAL EDUCA- TION
}

\begin{abstract}
The present study intends to select and analyze publishing with keywords violence, aggression and aggressiveness of 8 Brazilian journals of Physical Education indexed and labeled in extracts A1 to B2 Qualis system - CAPES area 21 of the past 10 years. Journals have been researched: Motives, Movement, Brazilian Journal of Sports Sciences, Brazilian Journal of Physical Education and Sports, Brazilian Journal of Science and Motion, Thinking Practice, Journal of Physical Education, Journal of Physical Activity and Health. Although the subject is important and even urgent, only 13 articles were published, $0.60 \%$ of published articles, which represents a low production in the theme.
\end{abstract}

Keywords: Violence. Aggression. Aggressiveness. Academic Production.

PRODUCIONES ACADEMICAS ACERCA DE VIOLÊNCIA, AGRESIÓN Y AGRESIVIDAD EM PERIÓDICOS BRASILEÑOS DE EDUCACIÓN FÍSICA

Pensar a Prática, Goiânia, v. 17, n. 3, p. 682-700, jul./set. 2014 


\section{Resumen}

Este estudio tiene como objetivo recopilar y analizar las publicaciones acerca de violencia, agresión y agresividad en 8 periódicos de Educación Física indexados y clasificados en los extractos A2 hasta B2 del Sistema Qualis - CAPES área 21, en los últimos 10 años. Se realizaron búsquedas por las palabras clave: violência, agresión y agresividad, en los periódicos: Motriz, Movimento, Revista Brasileira de Ciências do Esporte, Revista Brasileira de Educação Física e Esporte, Revista Brasileira de Ciência e Movimento, Pensar a Prática, Revista da Educação Física, Revista de Atividade Física e Saúde. Mientras la temática sea importante y mismo urgente, se encontraron solamente 13 artículos, 0,60\% de los artículos publicados, lo que representa una baja producción académica sobre la temática investigada.

Palabras-claves: Violencia. Agresión. Agresividad. Producción Académica.

\section{Referências}

ALBINO, B. S.; ZEISER, C. C.; BASSANI, J. J.; VAZ, A. F. Acerca da violência por meio do futebol no ensino de Educação Física: retratos de uma prática e seus dilemas. Pensar a Prática, Goiânia, v.11, n.2, p.139-147, maio/ago., 2008.

BOMFIM, D. L.; CAMPBELL, C. S. G.; MORAES, J. F. V. N.; FRANCO, A. M.; CUNHA, V. N. C.; FRANCA, N. M.; FERREIRA, S. M. B. Ocorrência de bullying nas aulas de Educação Física em uma escola do Distrito Federal. Pensar a Prática, Goiânia, v.15, n.2, p.302-317, abr./jun., 2012.

CAMPOS, P. A. F.; MELO, M. A.; ABRAHÃO, B. O. L.; SILVA, S. R. As determinações do estatuto de defesa do torcedor sobre a questão da violência: a segurança do torcedor de futebol na apreciação de espetáculo esportivo. Revista Brasileira de Ciências do Esporte, Campinas, v.30, n.1, p.924, set., 2008.

CANDREVA, T.; CASSIANE, V.; RUY, M. P.; THOMAZINI, L.; CESTARI, H. F.; PRODÓCIMO, E. A agressividade na educação infantil: o jogo como forma de intervenção. Pensar a Prática, Goiânia, v.12, n.1, p.1-11, jan./abr., 2009.

COUTINHO, R. X.; SOARES, M. C.; FOLMER, V.; PUNTEL, R. L. Análise da produção de conhecimento da Educação Física brasileira sobre o coti- 
diano escolar. Revista Brasileira de Pós-Graduação, Brasília, v.9, n.17, p. 491-516, jul., 2012.

LAVILLE, C.; DIONE, J. A construção do saber: manual da metodologia da pesquisa em ciências humanas. Trad. Heloisa Monteiro e Francisco Settineri. Porto Alegre: Artmed. Belo Horizonte: Ed. UFMG, 1999.

LEVANDOSKI, G.; CARDOSO, F. L. Percepção docente sobre as relações de agressividade, o lúdico e o "bullying" na escola. Pensar a prática, Goiânia, v.13, n.2, p.1-13, maio/ago., 2010.

LEVANDOSKI, G.; OGG, F.; CARDOSO, F. L. Violência contra professores de Educação Física no ensino público do estado do Paraná. Motriz, Rio Claro, v.17, n.3, p.374-383, jul/set., 2011.

MARCHLEWSKI, C.; SILVA, P. M.; SORIANO, J. B. A influência do sistema de avaliação Qualis na produção de conhecimento científico: algumas reflexões sobre a Educação Física. Motriz, Rio Claro, v.17, n.1, p.104-116, jan/mar., 2011.

MELlO, A. S.; COSTA, F. R.; SANTOS, W.; FERREIRA NETO, A. A construção de rivalidade e a da violência entre os grupos de capoeira de Piúma/ES. Pensar a Prática, Goiânia, v.13, n.2, p.1-17, maio/ago., 2010.

NASCIMENTO, E. F.; GOMES, R.; REBELLO, L. E. F. de S. Violência é coisa de homem? A "naturalização" da violência nas falas de homens jovens. Ciência \& Saúde Coletiva, v.14, n.4, Rio de Janeiro, jul./ago., 2009.

PALHARES, M. F. S.; SCHWARTZ, G. M.; TERUEL, A. P.; SANTIAGO, D. R. P.; TREVISAN, P. R. T. C. Lazer, agressividade e violência: considerações sobre o comportamento das torcidas organizadas. Motriz, Rio Claro, v.18, n.1, p. 186-199, jan./mar., 2012.

PRODÓCIMO, E., CAETANO, A., SÁ, A.S., SANTOS, F.A.G., SIQUEIRA, J.C.F. Jogo e emoções: implicações nas aulas de Educação Física Escolar. Motriz, Rio Claro, v.13, n.2, p.128-136, abr/jun., 2007.

PRODOCIMO, E., SILVA, R.G.C., MIGUEL, R.S., RECCO, K.V. Meninas também agridem? Estudo sobre agressão entre escolares. Educação em Foco, Juiz de Fora, v.15, n.1, p. 59-78, mar/ago, 2010.

Pensar a Prática, Goiânia, v. 17, n. 3, p. 682-700, jul./set. 2014 
PRODÓCIMO, E., FARENZENA, R.C., COSTA, R.R., SILVA, R.G.C., MATTOSINHO, P.V. Adolescentes brasileiros e a violência entre pares na escola: o fenômeno visto de dentro para fora. Revista Interacções, Portugal, v.25, p. 202-225, 2013.

REIS, H. H. B. Os espectadores de futebol e a problemática da violência relacionada à organização do espetáculo futebolístico. Revista Paulista de Educação Física, São Paulo, v.17, n.2, p.85-92, jul./dez., 2003.

REIS, H. H. B. Lei geral da copa, álcool e o processo de criação da legislação sobre violência. Movimento, Porto Alegre, v.18, n.1, p.69-99, jan./mar., 2012.

RIBOLLA, M.B., FIAMENGHI JR., G.A. Adolescentes na escola: representações sociais sobre violência. Revista Semestral da Associação Brasileira de Psicologia Escolar e Educacional (ABRAPEE), v.11, n.1, p. 111121, jan./jun., 2007.

ROSA, S.; LETA, J. Tendências atuais da pesquisa brasileira em Educação Física. Parte 1: uma análise a partir de periódicos nacionais. Revista Brasileira de Educação Física e Esporte, São Paulo, v.24, n.1, p.121-34, jan./mar., 2010.

SALVINI, L.; SOUZA, J.; MARCHI JUNIOR, W. A violência simbólica e a dominação masculina no campo esportivo: algumas notas e digressões teóricas. Revista Brasileira de Educação Física e Esporte, São Paulo, v.26, n.3, p.401-410, jul./set., 2012.

SILVA, C. A. F.; VOTRE, S. J. Encanto e fascínio: dimensões da sedução na educação. Pensar a Prática, Goiânia, v.12, n.3, p.1-12, set./dez., 2009.

SPOSITO, M. P. Um breve balanço da pesquisa sobre violência escolar no Brasil. Educação e Pesquisa, v.27, n.1, p.87-103, jan./jun., 2001.

STAREPRAVO, F. A.; MEZZANI, F.M. Esporte, relações Sociais e Violências. Motriz, Rio Claro, v.9, n.1, p.59-63, jan./abr., 2003. 
Recebido em: 24/03/2014

Revisado em: 15/05/2014

Aprovado em: 07/07/2014

Endereço para correspondência:

elaine@fef.unicamp.br

Elaine prodocimo

Universidade Estadual de Campinas - UNICAMP

Faculdade de Educação Física - FEF

Avenida Érico Veríssimo, 701, Cidade Universitária Zeferino Vaz, Barão Geraldo CEP 13.083-851, Campinas, SP, Brasil

Pensar a Prática, Goiânia, v. 17, n. 3, p. 682-700, jul./set. 2014 